\title{
Giant extra-axial posterior fossa tuberculoma in a three-year-old child
}

Sir, Intracranial tuberculosis, meningitis, and parenchymal tuberculomas, are still prevalent in some parts of the developing world. Of the intracranial tuberculomas, extra-axial tuberculomas are rare and may present with diagnostic dilemmas. ${ }^{[1]}$

A three-year-old girl presented with progressive enlargement of head, difficulty in walking and sitting, and progressive stiffness of all the four limbs since one year. There was no history of headache, vomiting, or fever. Developmental history suggested delay in acquiring milestones. On examination, there was macrocephaly, bulging anterior fontanelle, up gaze palsy, and increased tone in all the four limbs. Routine blood tests and chest X-ray were normal. Contrast computed tomography (CT) brain showed [Figure 1] a large ring enhancing $(51 \times 51$ $\times 60 \mathrm{~mm}$ ) lesion in the left posterior fossa compressing and shifting the fourth ventricle to right side causing obstructive hydrocephalous. There was extension of the lesion to supratentorial compartment through tentorial hiatus. A right ventriculoperitoneal shunt was done followed by definitive surgery. Midline suboccipital craniectomy and durotomy was done. At operation there was a large extra-axial lesion attached to tentorium superiorly and to brainstem medially compressing the cerebellum laterally. There was extension of the lesion to supratentorial compartment through tentorial hiatus. The tumor was yellowish, firm, and relatively avascular. Total excision of the lesion was done [Figure 2]. Histopatholgy was tuberculoma [Figure 3]. The patient improved postoperatively and was discharged on antituberculous treatment. At one-year follow up the patient is asymptomatic.

In developing countries, tuberculomas still account for about one-third of brain masses. ${ }^{[2]}$ Of the intracranial tuberculomas, extra-axial tuberculomas are extremely uncommon. ${ }^{[1,3]}$ Tuberculoma usually results from the hematogenous seeding of the tubercle bacilli to the leptomeninges and brain parenchyma, resulting in the formation of tubercles. The leptomeningeal tubercles 


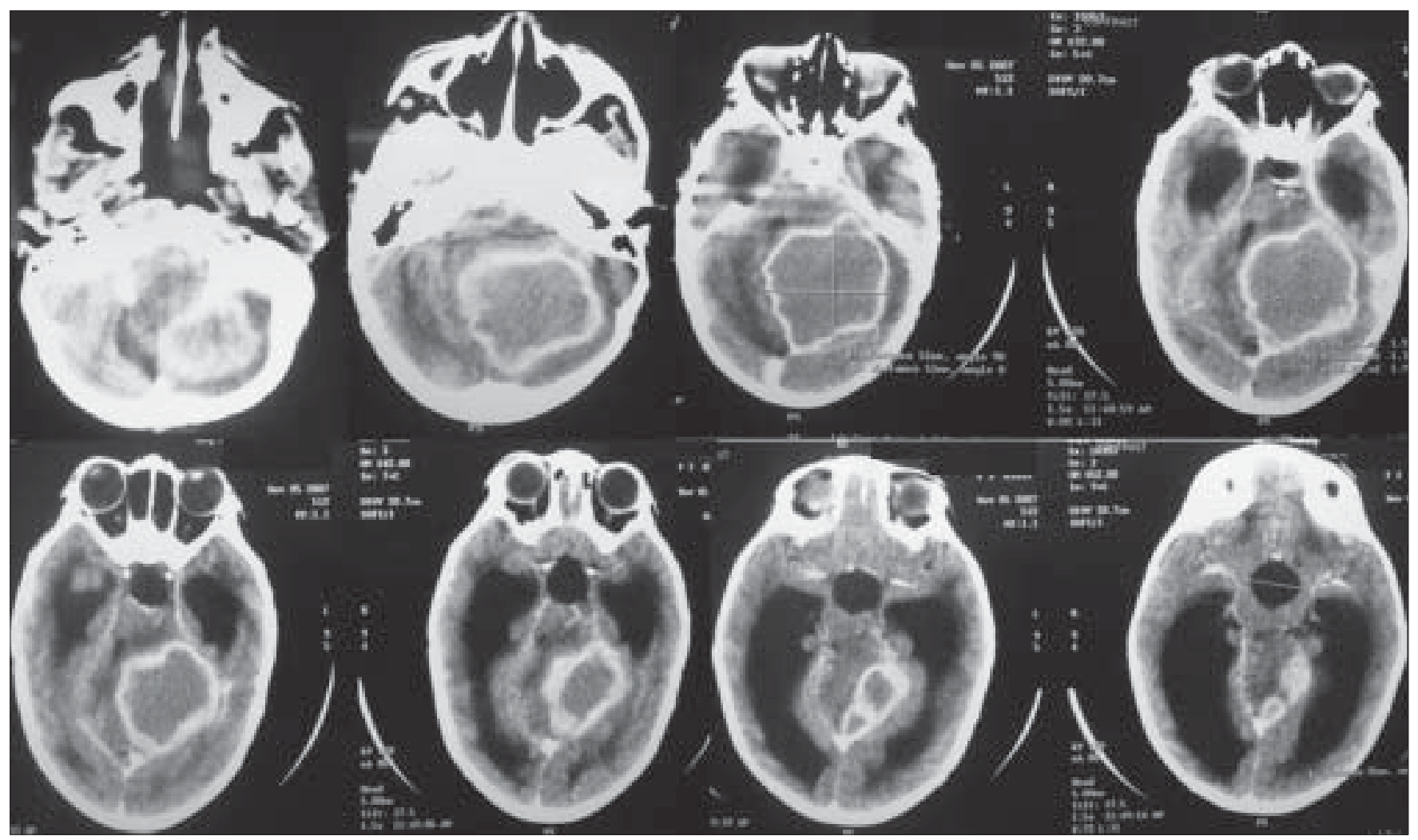

Figure 1: Postoperative contrast CT scan of the brain showing complete removal of the lesion

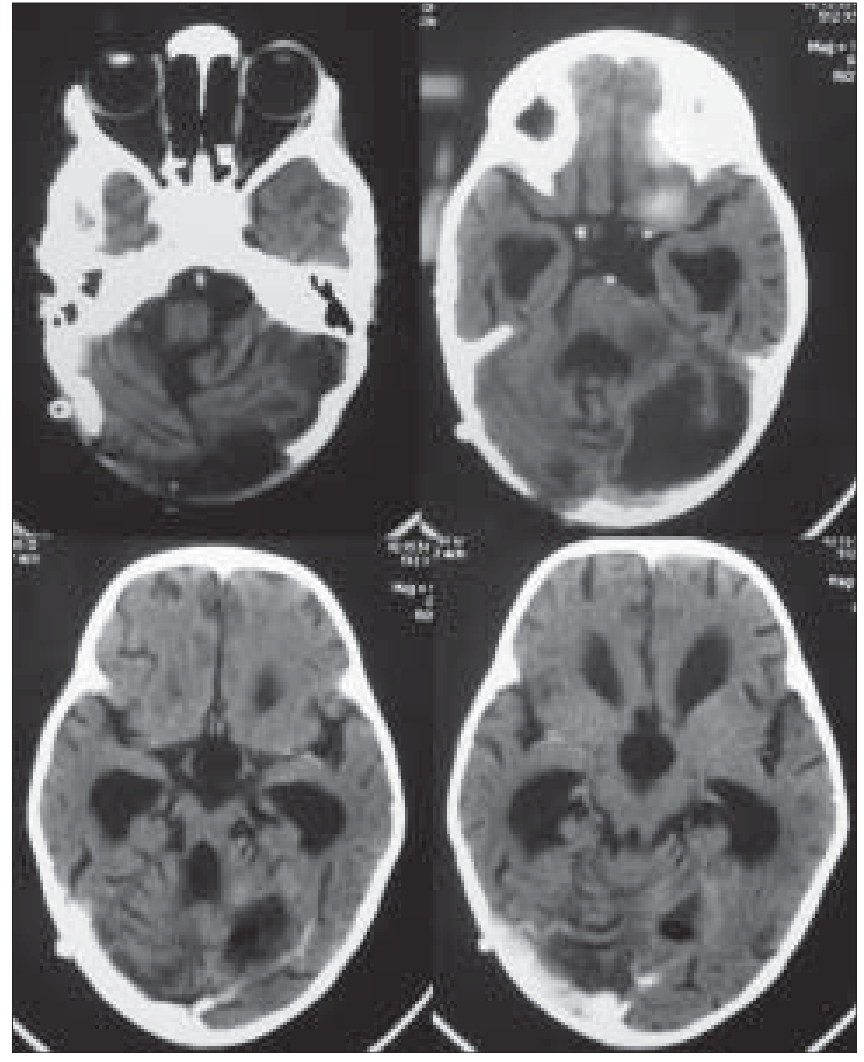

Figure 2: Contrast CT scan of the brain showing an enhancing large posterior fossa lesion extending to supratentorial compartment through tentorial hiatus with severe obstructed hydrocephalous

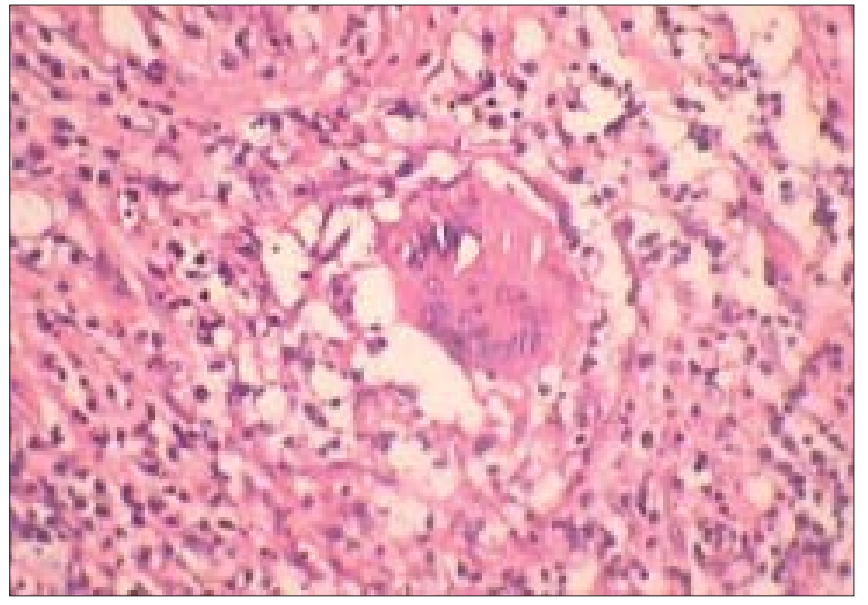

Figure 3: Photomicrography $(H \& E, \times 40)$ showing granulomatous inflammation with caseous necrosis surrounded by Langhans giant cell and lymphocytes

may rupture into the subarachnoid space resulting in meningitis or may remain confined to the meninges forming a hard fibrous mass attached to the dura which may present as tuberculoma-en-plaque, ${ }^{[4,5]}$ or extra-axial mass like meningioma. ${ }^{[3,6]}$

Extra-axial tuberculomas can present with the clinical picture like any other mass lesion, hence, preoperative differential diagnosis from other mass lesions is difficult. The differential diagnosis includes meningioma, 
lymphoma, metastatic tumor, and sarcoidosis. ${ }^{[4]}$ Findings of systemic infection and many of the usual laboratory correlates of infection may be absent. Cerebrospinal fluid examination may not be informative. ${ }^{[6]}$

$\mathrm{CT}$ and magnetic resonance (MR) imaging features are highly sensitive for tuberculoma, but their specificity for a definite diagnosis is low. Tuberculoma may be seen as a hypo or hyperdense, round or multilobar lesion on CT, and shows homogeneous or ring enhancement. ${ }^{[7]}$ The MRI signal characteristics of intracranial tuberculoma are extremely diverse. An isointense or hypointense core with a hyperintense rim on T2-weighted and FLAIR images is the most common presentation. Core hypointensity of lesion is related to necrosis and the large number of cells. ${ }^{[7]}$ MR spectroscopy may be complementary in the diagnosis and show elevated lipid peak, cholesterol ester, plasmalogen, and phenolic glycolipids. ${ }^{[1]}$ This finding may also help to differentiate tuberculomas from other disease conditions such as malignant tumors as well as the common extra-axial tumor like meningiomas. ${ }^{[7]}$ Large lesion with mass effect was the indication for surgery in this patient. Surgical excision not only helped to establish the histological diagnosis but also helped to resolve the compressive symptoms.

Vijay Parihar, Y. R. Yadav, Dhananjaya Sharma

Neurosurgery Unit, Department of General Surgery, NSCB Government Medical College and Hospital, Jabalpur, Madhya Pradesh, India.

E-mail:drvijayparihar@gmail.com

DOI: $10.4103 / 0028-3886.51304$

\section{References}

1. Khanna PC, Godinho S, Patkar DP, Pungavkar SA, Lawande MA. MR spectroscopy-aided differentiation: "Giant" extra-axial tuberculoma masquerading as meningioma. AJNR Am J Neuroradiol 2006;27: 1438-40.

2. Desai K, Nadkarni T, Bhatjiwale M, Goel A. Intraventricular tuberculoma: Case report. Neurol Med Chir (Tokyo) 2002;42:501-3.

3. Shindo A, Honda C, Baba Y. A case of an intracranial tuberculoma, mimicking meningioma that developed during treatment with anti-tuberculous agents. No Shinkei Geka 1999;27:837-41.

4. Dubey S, Devi BI, Jawalkar VK, Bhat DI. Tuberculoma en plaque: A case report. Neurology India 2002;50:497-9.

5. Bauer J, Johnson RF, Levy JM, Pojman DV, Ruge JR. Tuberculoma presenting as an en plaque meningioma. Case report. J Neurosurg 1996;85:685-8.

6. Lindner A, Schneider C, Hofmann E, Soerensen N, Toyka KV. Isolated meningeal tuberculoma mimicking meningioma: Case report. Surg Neurol 1995;43:81-4.

7. Wasay M, Kheleani BA, Moolani MK, Zaheer J, Pui M, Hasan S, et al. Brain CT and MRI findings in 100 consecutive patients with intracranial tuberculoma. J Neuroimaging 2003;13:240-7.

Accepted on 31-03-2009 